\title{
Entrevista - Marcos Napolitano História e música popular: entre a historiografia contemporânea e as práticas de ensino na Educação Básica
}

\author{
Interview - Marcos Napolitano \\ History and popular music: contemporary historiography \\ and teaching practices in basic education \\ Miriam Hermeto* \\ Olavo Pereira Soares**
}

Entrevista realizada por e-mail, dia 7 de fevereiro de 2017.

Marcos Napolitano é uma das principais referências nacionais sobre a música popular, tanto no campo da historiografia da cultura brasileira, quanto no que tange a produções editoriais voltadas para a formação continuada de professores. Doutor e Livre-docente (USP), é professor do Departamento de História e do Programa de Pós-Graduação em História Social da Universidade de São Paulo (USP). Atua também como assessor ad hoc da Fundação de Amparo à Pesquisa do Estado de São Paulo (Fapesp) e do CNPq, bem como na Coordenação de Aperfeiçoamento de Pessoal de Nível Superior (Capes). Líder do Grupo de Pesquisa "História e Audiovisual" (USP). Nesta entrevista, o professor Napolitano reflete sobre os rumos dos estudos sobre a música popular brasileira na historiografia brasileira e nas práticas de ensino desenvolvidas na educação básica. Relaciona as tradições historiográficas com as escolares, e aponta algumas possibilidades para as abordagens acadêmica e

\footnotetext{
* Doutora em História e Mestre em Educação (UFMG). Professora Adjunta do Departamento de História da Faculdade Filosofia e Ciências Humanas da Universidade Federal de Minas Gerais (Fafich/UFMG). Professora do Programa de Pós-Graduação em História da Fafich/UFMG. Belo Horizonte, MG, Brasil. miriamhermeto@gmail.com

** Doutor em Educação (USP). Professor Adjunto do Instituto de Ciências Humanas e Letras da Universidade Federal de Alfenas (UNIFAL-MG). Professor do Programa de Pós-Graduação em Educação (PPGE/UNIFAL-MG). Alfenas, MG, Brasil. olavopereirasoares@gmail.com
} 
didática sobre o tema que ampliem o campo de pesquisa ora constituído e o repertório cultural habitual de professores e estudantes.

Marcos Napolitano is one of the academic authorities in Brazilian popular music, both in the field of the historiography of Brazilian culture and in what stands to the editorial productions aimed at continued teacher training. Dr. Napolitano works in the Department of History, in the Post-Graduate Program in Social History and is a leader of the Research Group "History and Audiovisual" of the Universidade de São Paulo (USP). He also serves as ad hoc advisor to the Fundação de Amparo à Pesquisa do Estado de São Paulo (Fapesp) and $\mathrm{CNPq}$, as well as the Coordenação de Aperfeiçoamento de Pessoal de Nível Superior (Capes). In this interview, he talks about the tendencies of popular music studies in the Brazilian historiography and teaching practices developed for basic education. He makes comparisons of traditional and academic historiography, and points out some possibilities for the academic and didactic approaches on the issue that could broaden the field of current research and the standard repertoire of teachers and students.

Como você avalia o desenvolvimento da historiografia da música popular no Brasil nas duas últimas décadas e os rumos que hoje se anunciam para esses estudos?

Acho que uma das marcas da historiografia feita a partir do final dos anos 1990 foi o aprofundamento de estudos sobre a MPB e o samba, a partir dos trabalhos pioneiros na área de história e letras feitos nos anos 1980. Houve a incorporação de fontes novas, mais preocupação com a análise fonográfica a partir de uma perspectiva histórica e a verticalização de temas e objetos musicais ligados aos anos 1960 e 1970. Os temas do mercado, das vanguardas (Tropicalismo, por exemplo) e do engajamento, predominaram. Também devemos destacar a crescente problematização das hierarquias socioculturais em torno da música e a "naturalização" com que alguns gêneros musicais, como o próprio samba, eram tratados pelos pesquisadores, abrindo 
possibilidades para o estudo da música cafona, da música caipira, do axé e do rock, sem o clássico contraponto valorativo com a MPB canônica.

Que limites e possibilidades identifica para as práticas de ensino de História que se utilizam da música popular na educação básica?

Há muitas possibilidades e desafios. Entre as possibilidades "mais à mão", destaquem-se as abordagens clássicas, entre as quais aponto duas: samba e nacionalidade nos anos 1930 e MPB e resistência nos anos 1960 e 1970. Mas é preciso ir além desses temas clássicos. Já começam a surgir abordagens sobre a juventude, a partir do rap e do rock. Os gêneros nordestinos rurais podem servir para discutir a identidade e as representações do sertão e do sertanejo. A música caipira e sertaneja ainda é pouco utilizada para discutir conceitos como propriedade da terra, trabalho rural e paisagem cultural brasileira, mas já existem teses a respeito. O maior desafio é metodológico: como incorporar a escuta musical na análise da canção? Muitos professores ainda têm dúvidas e dificuldades a esse respeito. Outro desafio é heurístico: os professores devem tomar cuidado para utilizar uma canção como fonte histórica, mobilizando a gravação original da época estudada, informando-se sobre o seu suporte original (LP, 78rpm), evitando utilizar qualquer versão da canção proposta, baixada da internet, sem a devida contextualização.

Como os professores de educação básica devam relacionar o gosto musical dos estudantes e os objetivos específicos da aprendizagem histórica ao trabalhar com a música popular em seu planejamento?

Acho que deve haver uma combinação entre o gosto musical dos estudantes e a ampliação do seu repertório, como eixo do planejamento das atividades. A escola não deve ser mera reverberação do gosto geracional, construído a partir do mercado. Por outro lado, ela não pode impor um repertório aos alunos que não parta de suas experiências e preferências, buscando, obviamente, ir além. Não é uma negociação fácil, muitos alunos são surdos para novas experiências musicais, dada a extrema "tribalização" das audiências juvenis. Por outro lado, muitos professores têm um grande preconceito contra o gosto musical dos seus alunos. É preciso que as duas partes "desarmem" os seus ouvidos. [risos] O que importa é entender que a escuta de uma canção é parte da aula, de um tópico curricular, e não mera diversão em meio ao estudo 
"sério" de outros temas e fontes. O professor não deve ter medo de encarar a canção como um documento histórico, entre outros.

Que tipo de formação e cuidados metodológicos os professores de história na educação básica devem desenvolver para operar de maneira satisfatória com a música popular em sua prática de ensino?

Acho que a primeira tarefa do professor é conhecer a música, como ouvinte. Se o professor não tiver um repertório pessoal de escutas, dentro da própria $\mathrm{MPB}$, para além das canções-clichês, a coisa pode não funcionar. O professor deve conhecer várias canções, pensá-las em seus contextos (mesmo quando a "letra" não tem uma relação óbvia e direta com temas políticos e sociais), deve conhecer as diferenças de gêneros musicais de várias épocas (ou ao menos da história republicana brasileira), deve pré-selecionar canções para suas atividades ao longo do ano. Feito isso, que se dá em um plano mais informal e pessoal, o professor deve capacitar-se, conhecendo a bibliografia metodológica a respeito, visitando websites que tenham informação séria e checada, e frequentando cursos de capacitação. Na sala de aula, o professor deve construir um roteiro de abordagem das canções por ele utilizadas, valorizando a leitura da letra e a escuta atenta da canção. Deve apostar na sensibilidade e no repertório do aluno como ponto de partida, exigindo sempre mais. A escuta e a leitura devem ser repetidas à exaustão, se for preciso. Muitas vezes não prestamos atenção em letras riquíssimas e suas diversas camadas de sentido poético e histórico em uma audição rápida.

Você considera que existem períodos históricos que favoreçam mais (ou menos) uma formação que relacione ensino de história e música popular? Por quê?

Há períodos na história do Brasil em que a canção e a música popular foram parte orgânica do debate intelectual e da formação cultural do país, como nos anos 1930 e 1960/1970. Não por acaso, esses períodos são sempre lembrados nesse tipo de atividade escolar. No campo da "história geral", a canção (e a música, de maneira geral) ainda é pouco explorada nos materiais didáticos e atividades escolares. Quando muito, o rock é utilizado (ou citado en passant) nas aulas sobre os anos 1960, assim mesmo pontualmente. É claro, deve haver muitos professores pelo Brasil afora que se utilizam do rock em suas aulas, mas nas sugestões curriculares e materiais didáticos, isso é menos 
comum do que o uso da MPB e do samba para o estudo da história do Brasil. Menos utilizados ainda são o jazz, o rap e o folk de protesto (a não ser na sua interface com o pop, como em Bob Dylan e Joan Baez), cruciais para a experiência histórico-cultural norte-americana, por exemplo. Mais raro ainda é trazer a música erudita para a sala de aula e para os materiais didáticos, sobretudo aquelas obras produzidas entre o século XVIII e o século XX. Acho que os professores se sentem pouco à vontade nesse repertório ou têm medo que os alunos se rebelem, pois a música erudita exige uma escuta diferenciada da música popular - nem melhor, nem pior, mas diferente. Há também o desafio de mobilizar o repertório, selecionar trechos, abordar a relação entre música instrumental e experiência histórica, que exige uma formação mais específica do professor. Mas, como podemos ver, as possibilidades vão muito além dos usos mais comuns.

Entrevista recebida em 10 de fevereiro de 2017. Aprovada em 13 de março de 2017. 